\title{
Trial Introduction of a Bus Lane on A02: A Post-Mortem
}

\section{K. S. Weerasekera}

\begin{abstract}
Along Colombo - Galle road (A02) in Sri Lanka (one of the main radial arterial roads connecting southern Sri Lanka with the Colombo capital) few years back due to heavy in flow of morning traffic towards Colombo, a transit lane for public and private buses was introduced (kerb side lane was totally dedicated to buses only, as a solution to address this heavy inflow of traffic to Colombo). This kerb side transit lane was introduced between Dehiwala and Bambalapitiya on trial basis with the assistance of the Colombo city traffic police. Although the new introduction seem to be successful initially, but with passage of time due to unauthorized vehicles getting to the transit lane for their benefit and also buses not sticking to transit lane, led to a drop of efficiency in the transit lane and finally the trial effort was completely given up.
\end{abstract}

Through this study it is expected to look at the problem from queuing theory point of view and an attempt is made to find out where the failures took place and expect to bring in positive suggestions and corrective measures.

Keywords: Bus Lanes, Transit Lanes, Queuing Theory Models, Queuing Theory.

\section{Introduction}

The kerb side transit lane for buses (both public and private) was introduced along A02 (Colombo - Galle road) from Dehiwala via Wellawatta to Bambalapitiya on experimental basis for a short period of time around two weeks. During weekdays the roadway under consideration was made a 'clearway' \& the operation time was limited from 7:00am to 9:00pm to cover the peak flows. During the operation period the bus lane operation was monitored, and vehicles traveling along both lanes were separately counted. The transit lane was dedicated exclusively for buses and passenger carrying vans only. The purpose of the transit lane was to segregate transit traffic from other vehicles and to prevent interference of one from the other. Transit lanes are designed to provide faster and more reliable public transport for commuters in an attempt to increase support and to reduce the number of cars and other vehicles on the main road system during peak hours.

\section{Application of Queuing theory on Bus Lanes}

An attempt was made to apply queuing theory to study the operation of transit lanes (1) when smoothly operating under the strict supervision of police and, (2) when intruders violate the transit movement when police supervision was relaxed.

Figure 1 indicates lane operation before the transition lane was introduced (i.e. when all traffic towards Colombo was taken through the two lanes available towards Colombo direction).

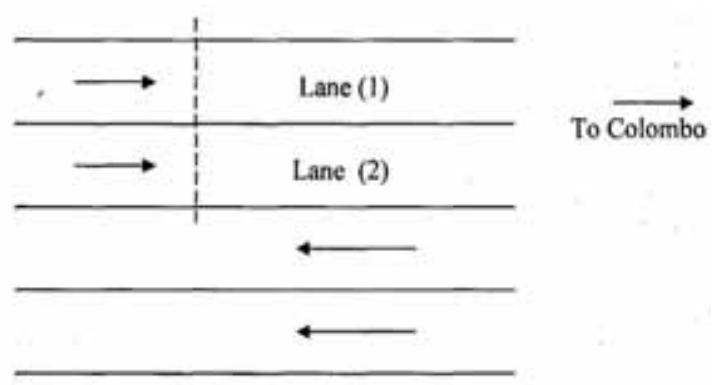

Figure 1 - General arrangement without transit lanes [ $\mathrm{M} / \mathrm{M} / 2$ queuing model ]

Figure 2 indicates when transition lane was introduces and with supervision of police when in smooth operation.

Eng. (Prof.) K. S. Weerasekera, BSc Eng (Moratuwa), MEngSc (UNSW), PhD (UNSW), FIE (Sri Lanka), CEng, IntPE(SL), MIE (Aust), CPEng, MIHT (UK), MASCE, Professor in Civil Engineering, Department of Civil Engineering, The Open University of Sri Lanka. 


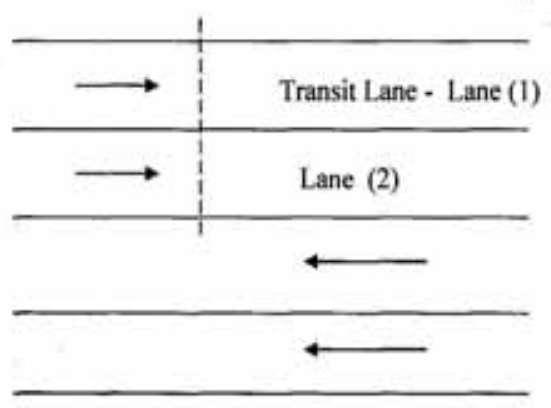

To Colomb

Figure 2 - With-flow transit lane on smooth operation [ 2(M/M/1) model]

\section{Methodology}

When applying queuing theory to the above two cases, the arrival rate of vehicles can be assumed to be a Poisson distribution for a random arrival of traffic (Adams, 1936). Pignataro (1973) further strengthened this assumption with further examples. If a roadside observer is noting the time difference between two consecutive vehicles passes (i.e. headways) in each lane, it can be considered as the service time of each vehicle in that lane. Hence the service time of each lane can be obtained.

Before Lane (1) is converted to a transition lane, total flow of traffic during peak hour towards Colombo was noted to be $2200 \mathrm{veh} / \mathrm{hr}$ (on both lanes). Total of busses and passenger carrying vans on both lanes was noted to be 450 veh/hr (i.e. $20 \%$ of total flow)

The study was conducted as two separate cases.

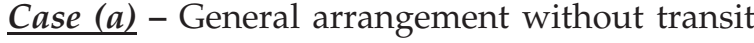
lane arrangement

$\underline{\text { Case }(b)}$ - With flow transit lane operation.

\section{Analysis \& Results}

Case (a) - General arrangement without transit lanes

The traffic is assumed to be equally distributed between the two lanes. This is similar to a $\mathrm{M} / \mathrm{M} / 2$ type queuing model with 2 service facilities.

The model parameters are as follows:
The arrival pattern is a Poisson distribution (Adams 1936; Pignataro 1973). It was also observed that the cumulative flow curve was as indicated in Figure 3.

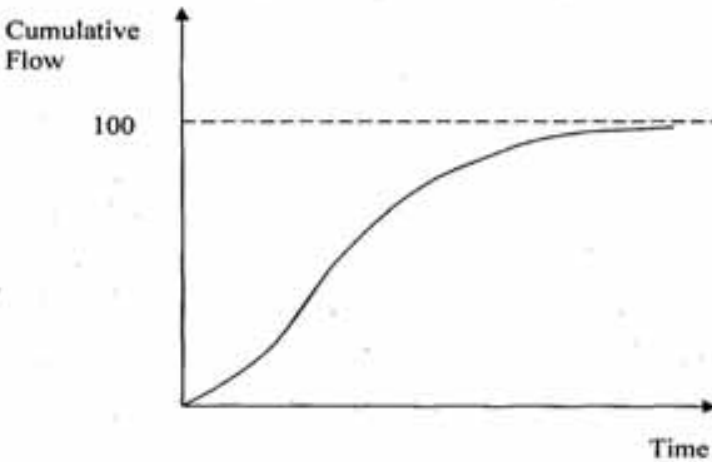

Figure 3 - Cumulative arrival flow

If the flow is being observed from a roadside fixed point, the average rate of service of a lane $(\mu)$ can be considered as the reciprocal of average headway between two consecutive vehicles.

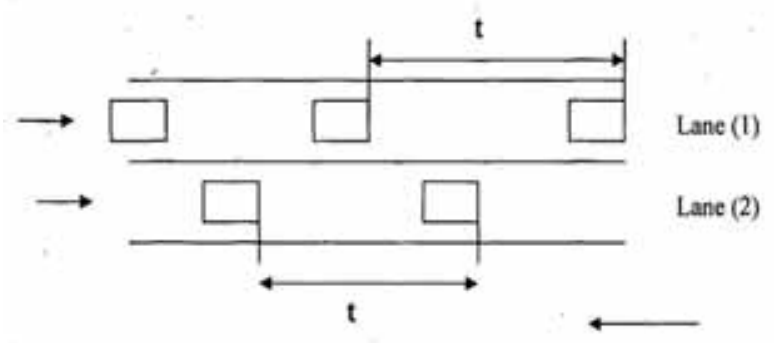

$\mathrm{t}$ - average headway of both lanes

Figure 4 - The average headway of both lanes (when without transit lanes)

Flow in lane $(1)=$ Flow in lane $(2)=\mathrm{q}$ $\mathrm{q}=2200 /(2 \times 3600)=0.305 \mathrm{veh} / \mathrm{sec} /$ lane Average headway (i.e. average service time) = $1 / \mathrm{q}=1 / 0.305=3.27$ secs

Service rate of a lane $=\mu=1 /$ (Average headway) $=0.305 \mathrm{veh} / \mathrm{sec} /$ lane

\section{Case (b) - With-flow transit lane on operation}

When transit lane is operating, 450 vehicles traveled on transit lane and balance will take the other lane. If assumed that no transit lane 
violators (i.e. the ideal condition). This will behave as two $\mathrm{M} / \mathrm{M} / 1$ models.

Flow in lane $(1)=450 / 3600=0.125$
veh/sec/lane
$\begin{aligned} & \text { Flow in lane }(2)=1750 / 3600=0.486 \\ & \text { veh } / \mathrm{sec} / \text { lane }\end{aligned}$

Hence,

Service rate of lane (1) $=\mu_{1}=0.125$ veh/sec/lane

Service rate of lane (2) $=\mu_{2}=0.486$ veh/sec/lane

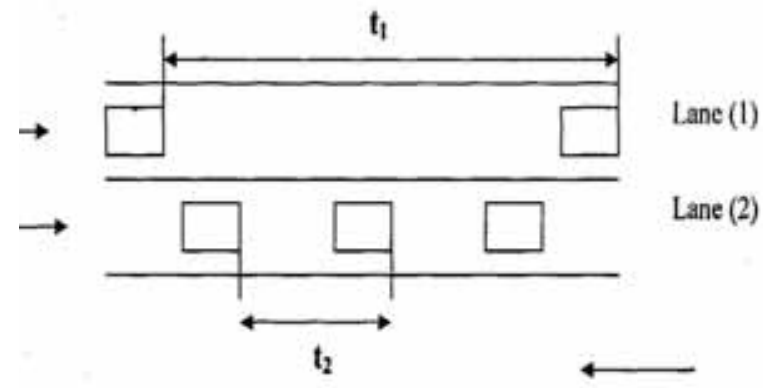

Figure 5 - The average headway of lane ( 1 ) \& lane ( 2 ) [with flow transit lane on operation]

$t_{1}=$ average headway in lane (1)

$t_{2}=$ average headway in lane (2)

Service time of lane (1); $t_{1}=1 / 0.125=8.0$ secs Service time of lane (2); $t_{2}=1 / 0.486=2.057$ secs

$t_{1}>t_{2}$

\section{Conclusions}

Hence now lane (1) has a higher service time and lane (2) has a lower service time, this in reverse will drop the service rate $\left(\mu_{1}\right)$ of lane (1) and increase the pressure on the service rate of lane (2). If the saturation of lane (2) has occurred, then the transit lane operation may bring down the total vehicle throughput on the road. But though the number of vehicles in transit lane has dropped, due to the high occupancy rate in vehicles occupying this lane, there will be an overall improvement in the total passenger travel time.

Effect due to Transit Lane occupied by banned Vehicles
Breaching of transit lane regulations occur when unauthorized vehicles get on to the transit lane and use for their benefit. Once this happened with relaxing of police monitoring the transit lane discipline, the efficiency of the transit lane dropped.

Wei and Chong (2002); Viegas et al. (2007) have indicated the problem of veering into transit lanes to dodge traffic queues which is often happening when monitoring is relaxed. Shapiro (2008) discusses the role played by monitoring with the help of fixed cameras in maintaining discipline.

In queuing theory, model used for transit lanes shown when operating smoothly as shown in Figure 2, it was shown that the two lanes were behaving as two $M / M / 1$ models. It should be noted that this behaviour will prevail only if there is no mixing of vehicles between the two lanes. If more transit lane breaching is occurring, the model will stop behaving as two separate $\mathrm{M} / \mathrm{M} / 1$ queues, and neither will behave as $\mathrm{M} / \mathrm{M} / 2$ model.

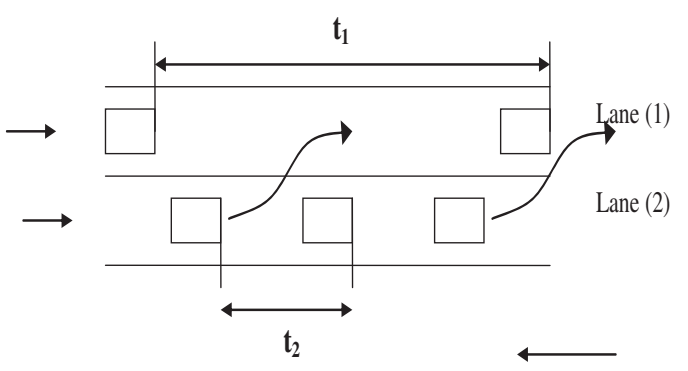

Figure 6 - Breaching of transit lane regulations

When transit lane regulations are violated it can affect the function of the transit lane in following manner.

- Smooth flow in transit lane can get disturbed due to unauthorized lane changing by other vehicles along the transit lane as indicated in Figure 6.

- Vehicle flow in transit lane will increase while decreasing the level of service in the transit lane.

- Average speed in the transit lane will reduce.

- When unauthorized vehicles get on to the smooth flowing transit lane at unexpected times, the well maintained headway between the vehicles in transit lane may get affected, causing harmful influence on the 
expected regularity and punctuality of the bus service.

\section{Recommendations}

Police can enforce the transit lane regulations by stopping the violators and warning them in the initial stage. If it seems that punishment by warning is not severe enough fines can be imposed on the transit lane violators. Police can operate random checking points and catch the transit lane violators in a similar manner to catching the high speed drivers and alcoholic drivers.

\section{References}

1. Adams, W. F., "Road Traffic Considered as a Random Series", Journal of the Institution of Civil Engineers, Vol. 4, November, 1936, pp. 121-130.

2. Gross, D. and Harris, C. M., Fundamentals of Queuing Theory, 2nd Edition, John Wiley \& Sons, New York, 1985

3. Pignataro, L. J., Traffic Engineering, Theory and Practice, Prentice-Hall, Inc., Englewood Cliffs, New Jersey, 1973

4. Shapiro, J., "City tells Downtown skeptics the Broadway bus lane 'seems' to work", Downtown Express, Vol. 21, No. 33, December, 2008, pp. 19-25.

5. Viegas, J. M., Roque, R., Lu, B. and Vieira, J., "The Intermittent Bus Lane System: Demonstration in Lisbon", 86th TRB Annual Meeting - 2007.

6. Wei, L., Chong, T., "Theory and Practice of Bus Lane Operation in Kunming, 2002, pp. 68-72. 